\title{
Synthesis and Characterization of a Red Clay Based New Composite Ceramic Material
}

\author{
Youness Rakhila, Amine Ezzahi*, Abdellah Elmchaouri, Allal Mestari \\ Chemistry Physics \& Bioorganic Chemistry Laboratory, Faculty of Science and Techniques, Mohammedia, Morocco \\ Email: ^mr.ezzahi@gmail.com
}

How to cite this paper: Rakhila, Y., Ezzahi, A., Elmchaouri, A. and Mestari, A. (2018) Synthesis and Characterization of a Red Clay Based New Composite Ceramic Material. Advances in Materials Physics and Chemistry, 8, 295-310.

https://doi.org/10.4236/ampc.2018.87020

Received: April 16, 2018

Accepted: July 24, 2018

Published: July 27, 2018

Copyright () 2018 by authors and Scientific Research Publishing Inc. This work is licensed under the Creative Commons Attribution International License (CC BY 4.0).

http://creativecommons.org/licenses/by/4.0/

\begin{abstract}
In this study, a new composite ceramic material using a red clay matrix with different amount of clinker from the cement industry has been developed. The aim is to valorize some natural resources such as red clay and sub-products from the cement industry as clinker in order to develop new materials for industrial and/or catalytic uses. Raw materials were grounded in order to reduce the particle size and obtain a homogeneous slip. The samples were mixed and compressed into pellets and undergo a heat treatment up to $1100^{\circ} \mathrm{C}$. Geotechnical characterization has been carried out. Firing proprieties (shrinkage, water absorption, and mechanical resistance to the inflection) were measured. The composition of the ceramic material was investigated by X-ray diffraction, XRF, SEM and EDS methods. The incorporation of clinker in the ceramic composite material up to $50 \mathrm{wt} \%$ exhibits good behaviors (physical and mechanical proprieties) and can be used as a ceramic product.
\end{abstract}

\section{Keywords}

Red Clay, Clinker, Characterization, Physical Chemical Properties, Ceramic, Composite Materials

\section{Introduction}

The mineral materials are obtained from the earth. The latest effort in this direction was made nearly five centuries later by the joint nomenclature committees (JNCs) of the Association Internationale pour l'Etude des Argiles (AIPEA) and the Clay Minerals Society (CMS). The JNCs have defined "clay" as "a naturally occurring material composed primarily of fine-grained minerals, which is generally plastic at appropriate water contents and will harden with (sic) dried or fired" [1].

Likewise, the term "clay mineral" is difficult to define. As a first approxima- 
tion, the term signifies a class of hydrated phyllosilicates making up the fine-grained fraction of rocks, sediments, and soils. The definition that the JNCs have proposed is "phyllosilicate minerals and minerals which impart plasticity to clay and which harden upon drying or firing". Since the origin of the material is not part of the definition, clay mineral (unlike clay) may be synthetic [1] [2].

Although particle size is a key parameter in all definitions of clay, there is no generally accepted upper limit. Clays are characterized by grains (beads) having a size approximately for $2 \mu \mathrm{m}$ which gather together to give polycrystalline aggregates [3]. They relate to natural microporous minerals consisted of particles of very fine texture with various scales. In the macroscopic scale, these particles are often associated with minerals such as the quartz, the feldspar, etc., and in the microscopic scale, the particles correspond to materials of two-dimensional structure in leaf [1] [3]. The slim waist of these particles and the character flattened by these constituent minerals, gives to the clay a large specific surface.

The structure of the natural clay consists of a pile of lamellae's leaves which are organized in flat layers bi-dimensional consisting of tetrahedral and octahedral structural units connected by their summits [2] [4].

The red clay consists of a mixture of natural minerals called "clay minerals" (Quartz, feldspars, iron oxide, oxidizes titanium, earthy oxide, etc.). In clay, clay minerals with stronger contents are: The silica (quartz, cristobalite, tridymite), Oxides and hydroxides of aluminum (corundum, gibbsite, diaspore, boehmite...), Carbonates (dolomite, diobertite, siderite, calcite, aragonite...) and iron minerals (lepidocrocite, maghemite, etc.).

The red clays are used as raw materials in many industrial fields (ceramics, paper, paint, catalysis...) [5] [6] [7]. Their applications are tightly dependent upon their structure, composition, and physical attributes.

Another very important material, the cement, the cement is a crystalline compound of calcium silicates and other calcium compounds having hydraulic properties. It is a material with adhesive and cohesive properties which make it capable of bonding minerals fragments into a compact whole. For constructional purposes, the meaning of the term "cement" is restricted to the bonding materials used with stones, sand, bricks, building stones, etc. The cements of interest in the making of concrete have the property of setting and hardening under water by virtue of a chemical reaction with it and are, therefore, called hydraulic cement.

The cement is produced by carrying in a temperature of $1450^{\circ} \mathrm{C}$ of a mixture of limestone and clay. We obtain then called hard nodules to clinker. The added clinker is very finely crushed to obtain the cement "Portland" [8].

Some other mineral elements added to the clinker during its grinding such as milkmen of blast furnaces, ashes of thermal power plants, fillers limestones, natural or artificial pozzolana, allows obtaining various categories of cements.

Any heterogeneous material could be qualified as composite material [9]. Nevertheless, generally a more restrictive definition is given. 
A composite is a material consisting of two (or more) immiscible phases with different properties and roles. One, continuous, is called a matrix and the other, discontinuous, called reinforcement. This mixture possesses new properties and we look for by associating them a set of superior performances in components taken separately [10].

The reinforcement often assures the mechanical holding and the matrix, the cohesion and the energy transfer. The reinforcing materials give the composites their mechanical characteristics: rigidity, resistance to rupture, hardness... They also make it possible to modify some physical properties such as thermal behavior, abrasion resistance or electrical properties.

The properties of composite materials depend on three factors [11]:

- The nature and properties of the constituent materials,

- The geometry and distribution of the reinforcement,

- Interactions between constituents and the nature of the matrix-reinforcement interface.

The reinforcement will be characterized by its shape, its size, its concentration and its orientation. The reinforcement concentration is defined by the volume or mass fraction. This is a parameter determining the properties of the composite.

Its distribution in the volume is also because many properties depend on it as shown, for example, by the theory of percolation.

If it is uniform, the measurements will not depend on the measurement point. According to the geometry and the orientation of the reinforcement, it is possible to control the anisotropy of desired characteristics of the composite.

In this study the clinker has been used as adjuvant incorporated in clay composites, by adding various amount of clinker to red clay. The synthesized ceramic materials were characterized by physical, chemical and mechanical tests.

\section{Materials and Methods}

\subsection{Materials}

The red clay samples were collected from the area of Ben-Ahmed district (location-33 $06^{\prime} 43^{\prime \prime} \_N$ and $7^{\circ} 24^{\prime} 21^{\prime \prime} \_$) of Morocco. Clinker was collected from cement industry, CIMAT Khouribga situated in the middle of Morocco.

\subsection{Sample Preparation}

Clinker and clay sample were ground in powder form. Different percentages of clinker (Table 1) were thoroughly mixed with clay and granulated for better compaction.

Table 1. Composition in wt $\%$ of the ceramic material samples.

\begin{tabular}{ccccccccccc}
\hline Ceramic material number & 1 & 2 & 3 & 4 & 5 & 6 & 7 & 8 & 9 & 10 \\
\hline Red clay (wt\%) & 100 & 85 & 75 & 65 & 50 & 40 & 20 & 15 & 10 & 0 \\
Clinker (wt\%) & 0 & 15 & 25 & 35 & 50 & 60 & 80 & 85 & 90 & 100 \\
\hline
\end{tabular}


The optimal humidity of the mixtures fluctuated between $10 \%$ and $12 \%$ with variation of the mixture contents. $5 \mathrm{~g}$ of humid mixtures were pressed at $10 \mathrm{MPa}$ in the form of a circle with diameter of $50 \mathrm{~mm}$ and around $2 \mathrm{~mm}$ thick, dried at $110^{\circ} \mathrm{C}$ for $24 \mathrm{~h}$ in a Heraeus drying oven until a constant weight was reached then heated in a programmable oven (Controller P 320 Nabertherm). A thermal program (Figure 1) with three stages is established $\left(250^{\circ} \mathrm{C}, 750^{\circ} \mathrm{C}\right.$ and $\left.1100^{\circ} \mathrm{C}\right)$ the gradient rise of $3^{\circ} \mathrm{C} / \mathrm{min}$ and the duration of each stage is 2 hours. Then various physical properties of prepared samples were analyzed.

\subsection{Methods}

The raw materials and ceramics were characterized using various methods. To determine the chemical composition a Siemens sequential X-Ray Fluorescence Spectrometer model SRS 200 was used. The mineralogical composition was determined by XRD, using the powder method, performed with a Siemens, X-Ray Diffractometer model D5000, with monochromatic wavelength $\lambda \mathrm{Cu}-\mathrm{K} \alpha$, at 2 range of $2^{\circ}-70^{\circ}$. Morphological observations were carried out by scanning electron microscopy (SEM) using a Hitachi-3400N. Chemical micro analyses were developed using energy dispersive spectroscopy (EDS) with an Oxford (Penta FET-125 Precision). Granulometric distribution was determined using a laser diffraction particle size distribution analysis with a Granulometer Model-Microtrac S3500.

The fired samples were subjected to various physical analyses. Bulk density, water absorption and apparent porosity were determined by Archimedes's immersion technique by keeping the sample in boiling water according to ASTM C20-00 [12]. Linear shrinkage was determined after drying at $110^{\circ} \mathrm{C}$ and after firing ASTM C356-10 [13]. The mechanical strength and Young's modulus were studied by Universal Testing Machine (UTM Testometric Model FS-300KN) according to ASTMC674-88 [14].



Figure 1. The thermal program for heat treatment of red clay ceramic materials. 


\section{Results and Discussions}

\subsection{Characterization of the Raw Materials}

Results of chemical FX analyses of the raw materials (Table 2) show that the red clay is relatively rich in silica (59.32\%) calcium (2.1\%) and iron oxide (4.29\%).

The presence of potassium oxide $(0.18 \%)$ and sodium $(0.8 \%)$ in clay raw material is probably due to the relatively large amount of illite content. The content, relatively important in magnesium $(\mathrm{Mg})$, is probably due to the presence of double carbonate and/or to the substitution of the ion $\mathrm{Al}^{+3}$ by the ion $\mathrm{Mg}^{+2}$ in the octahedral sites of the material. Those results can be confirmed by the $\mathrm{X}$ - rays diffraction spectra (Figure 2(a) and Figure 2(b)).

The XRD patterns indicate that the clay sample was (Figure 2(a)) mainly illite type with significant amount of quartz and calcite and with traces of hematite

Table 2. Chemical compositions (in wt\%) of red clay and clinker as determined by X-ray fluorescence.

\begin{tabular}{ccccccccccccc}
\hline wt\% & $\mathrm{CuO}$ & $\mathrm{ZnO}$ & $\mathrm{CaO}$ & $\mathrm{K}_{2} \mathrm{O}$ & $\mathrm{MgO}$ & $\mathrm{Na}_{2} \mathrm{O}$ & $\mathrm{P}_{2} \mathrm{O}_{5}$ & $\mathrm{SO}_{3}$ & $\mathrm{Al}_{2} \mathrm{O}_{3}$ & $\mathrm{Fe}_{2} \mathrm{O}_{3}$ & $\mathrm{MnO}_{2}$ & $\mathrm{SiO}_{2}$ \\
\hline Clay & 0.01 & 0.02 & 2.10 & 0.18 & 1.57 & 0.80 & 0.12 & 0.75 & 11.44 & 4.29 & 0.09 & 59.32 \\
Clinker & 0.002 & 0.001 & 62.15 & 0.40 & 1.5 & 0.3 & 0.12 & 0.75 & 4.88 & 2.86 & 0.002 & 19.07 \\
\hline
\end{tabular}



$2 \theta \quad \lambda \mathrm{Cu}-\mathrm{Ka}$

(b)



Figure 2. X-ray diffraction pattern (a) red clay (b) clinker $(\mathrm{Q}=$ quartz, $\mathrm{M}=$ Muscovite, $\mathrm{H}=$ hematite, $\mathrm{D}=\mathrm{Dolomite}, \mathrm{C}=$ calcite). 
and dolomite.

The clinker chemical results show that it is mainly a mixture of calcite $\mathrm{CaO}$ (62.15\%) quartz $\mathrm{SiO}_{2}$ (19.07\%), $\mathrm{Al}_{2} \mathrm{O}_{3}$ (4.88\%), $\mathrm{Fe}_{2} \mathrm{O}_{3}$ (2.86\%) and $\mathrm{MgO}$ (1.5\%).

XRD patterns of the clinker sample (Figure 2(b)) show that it is almost formed of calcite and quartz with traces of hematite.

Particle size distribution of red clay sample's data (Figure 3) indicated that the sample is classified as silty clay and usable for ceramic products.

The particle size distribution of the red clay and clinker (Figure 3(a) and Figure 3(b)) demonstrated the existence of two maxima peaks of each material at approximately $55 \mu \mathrm{m}$ and $23 \mu \mathrm{m}$ respectively.

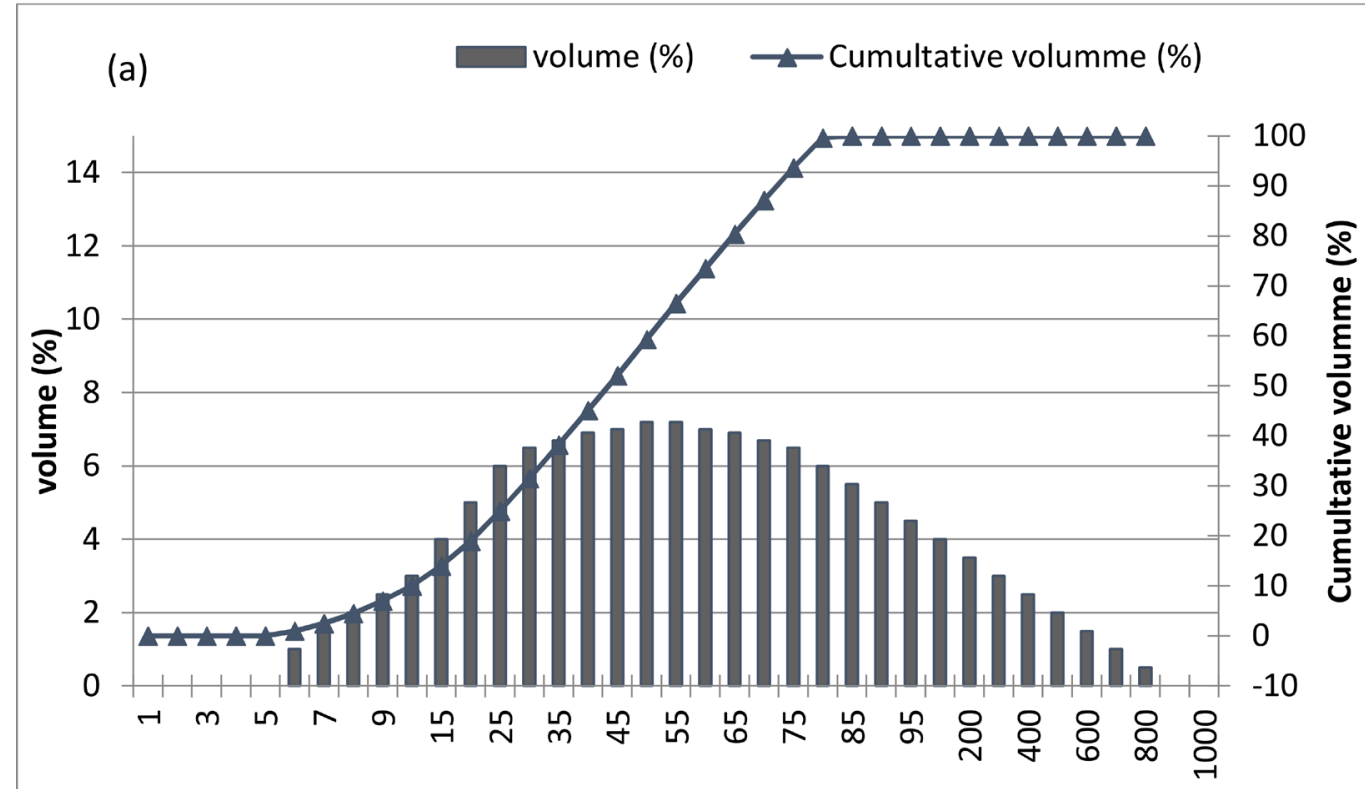

(b)

volume (\%) $\longrightarrow$ Cumultative volumme (\%)

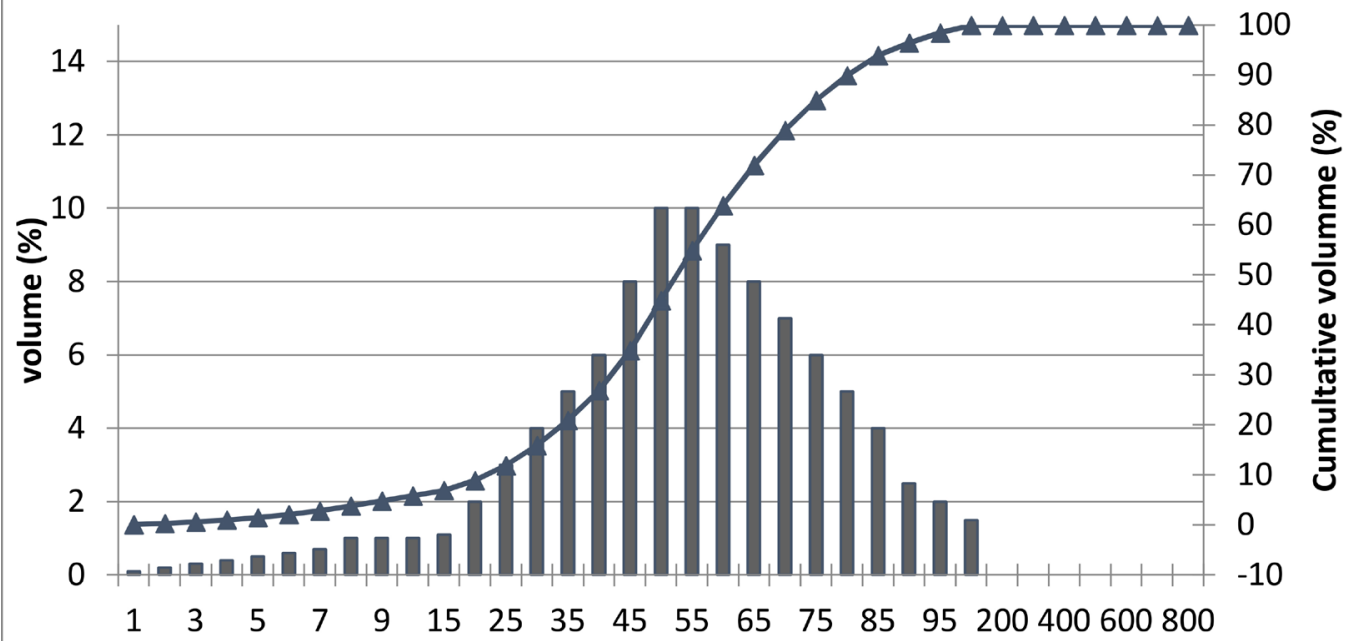

Figure 3. Particle size distribution: (a) red clay sample (b) clinker. 
The chemical composition of these mixtures has been performed (Table 3). The analysis showed that the silica, calcium and iron oxide percentage increased as the clinker amount increased.

The main crystalline phases identified by XRD (Figure 4) after samples were heated at $1100^{\circ} \mathrm{C}$.

A comparison of the XRD patterns (Figure 4) obtained for red clay and the ceramic materials at $15 \mathrm{wt} \% ; 25 \mathrm{wt} \% ; 50 \mathrm{wt} \%$ and $100 \mathrm{wt} \%$ clinker sintered at $1100^{\circ} \mathrm{C}$.

Although the same crystalline phases were identified, the intensities of the main peaks corresponding to quartz, calcite and dolomite, situated in the range $20^{\circ}-48^{\circ}(2 \theta)$, increase as clinker content increased indicating that these crystalline phases are present in smaller amounts. This suggests that the amount of glassy phase increases as the clinker content increases as expected considering the information taken from the equilibrium phase diagram for the system of the main components [15].

Table 3. Chemical composition of the composite ceramic materials as determined by $\mathrm{X}$-ray fluorescence.

\begin{tabular}{ccccccccccccc}
\hline wt\% & $\mathrm{CuO}$ & $\mathrm{ZnO}$ & $\mathrm{CaO}$ & $\mathrm{K}_{2} \mathrm{O}$ & $\mathrm{MgO}$ & $\mathrm{Na}_{2} \mathrm{O}$ & $\mathrm{P}_{2} \mathrm{O}_{5}$ & $\mathrm{SO}_{3}$ & $\mathrm{Al}_{2} \mathrm{O}_{3}$ & $\mathrm{Fe}_{2} \mathrm{O}_{3}$ & $\mathrm{MnO}_{2}$ & $\mathrm{SiO}_{2}$ \\
\hline $\begin{array}{l}\text { Ceramic } \\
\text { Material }\end{array}$ & 0.004 & 0.01 & 6.95 & 0.15 & 1.17 & 0.62 & 0.12 & 0.84 & 12.11 & 5.53 & 0.04 & 61.55
\end{tabular}

$100 \%$ wt clinker

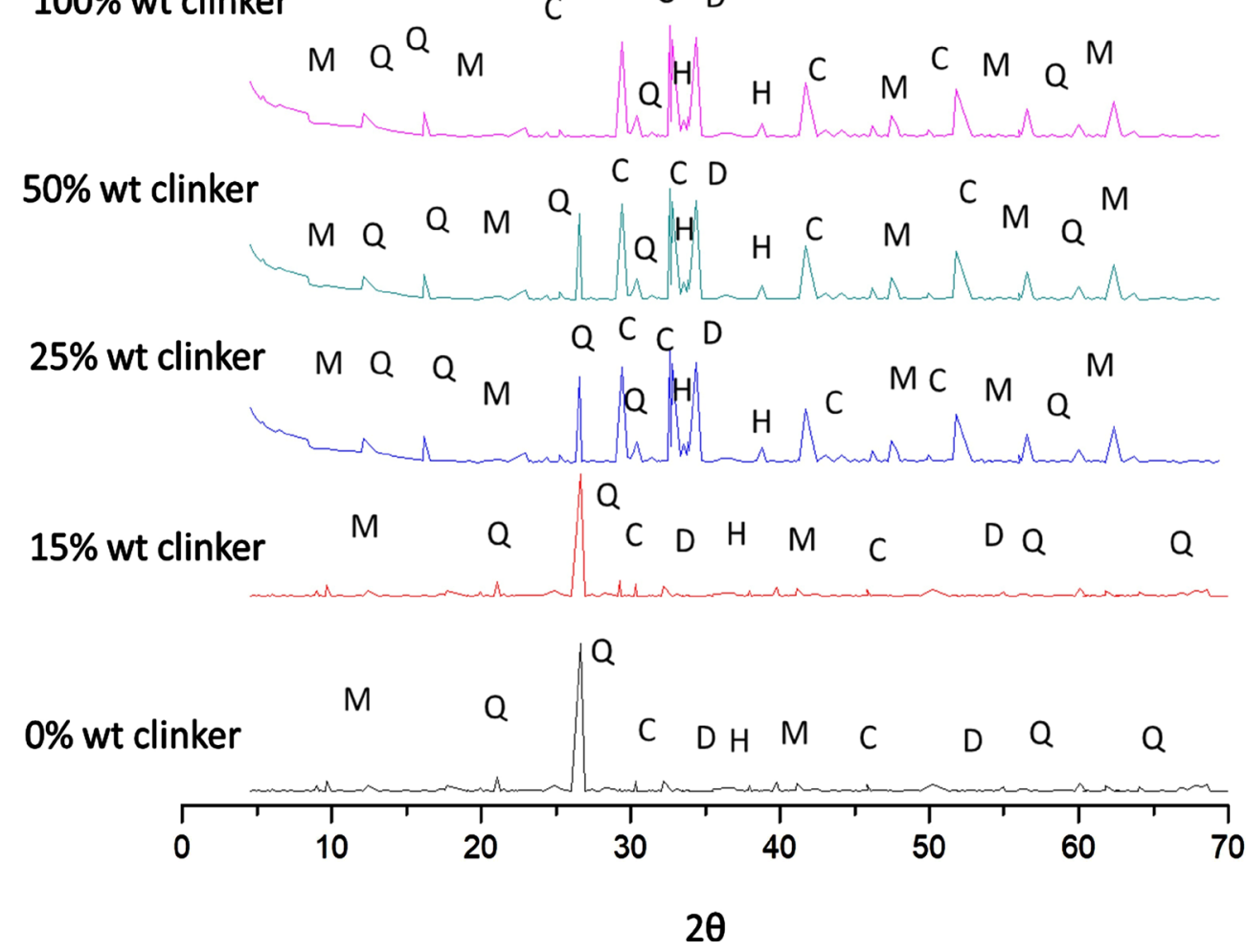

Figure 4. XRD pattern of the composite ceramic material (0 wt\%; $15 \mathrm{wt} \% ; 25 \mathrm{wt} \% ; 50 \mathrm{wt} \%$ and 100 wt $\%$ clinker) fired at $1100^{\circ} \mathrm{C}$. 


\subsection{Physical Properties}

1) The shrinkage

The shrinkage depends primarily on clay mineralogical composition, texture, shaping conditions of the paste and amount of the additive material (clinker). The shrinkage phenomenon is closely related to the calcination phenomenon that occurs during firing of the samples. During the heat cycle, the microstructure is taking place between the grains, in order to minimize the excess of interface energy, which is generally accompanied by a decrease in porosity. The dimensional variation is related to the elimination of some components (with eventually creation of an internal gas pressure) and to the structural reactions and transformations.

The shrinkage coefficient of the reference ceramics (from clay without clinker) is reduced after sintering (Figure 5(a)).

The addition of clinker decreases the shrinkage to a very low level $(0.49 \%$ for $30 \%$ of clinker). In order to enhance this phosphogypse [16], another study of the incorporation of phosphogypse in the building bricks gave a shrinkage exceeds $7.2 \%$. A. Arib and all [17] work on the characterization of clay-based ceramics gets better as shrinkage $1 \%$ which confirmed our results.

2) Water absorption

The water absorption is the main factor for the durability of the final product. a high water absorption would contribute to a rapid deterioration of the product. [18]

According to the water absorption results (Figure 5(b)), it's decreased as the amount of clinker in the ceramic materials increased. The decrease in water absorption coefficient influences the mechanical properties and durability of the sample making it more resistant and more durable. Xu Lingling and all [19] have found a high values about $17 \%$ for the characterization of the bricks built with incorporation of fly ashes.

3) Density

In general the absolute density of the clay (non-porous) is less than $2.8 \mathrm{~g} / \mathrm{cm}^{3}$. It's related to the chemical composition of the raw material (higher density with high concentrations of aluminum and iron) and the product structure (higher density if it is crystalline).

Adding clinker decreases the density up to $0.64 \mathrm{~g} / \mathrm{cm}^{3}$ (35 wt\% of clinker) (Figure 5(c)). It appears that there are no other studies to compare those results either for bricks built with marble $\left(2 \mathrm{~g} / \mathrm{cm}^{3}\right)$ [20] or for bricks built with olive's waste $\left(2.005 \mathrm{~g} / \mathrm{cm}^{3}\right)[21]$.

4) Apparent porosity

The porosity is the most important parameter for all the ceramic properties because it influences the strength, water absorption and the permeability of the ceramics. The porosity can be opened or closed. Depending on the product, It is sought different porosity, low porosity $(<20 \%)$ for the tiles and exposed brick and high porosity $(>40 \%)$ for certain types of low thermal conductivity bricks. 


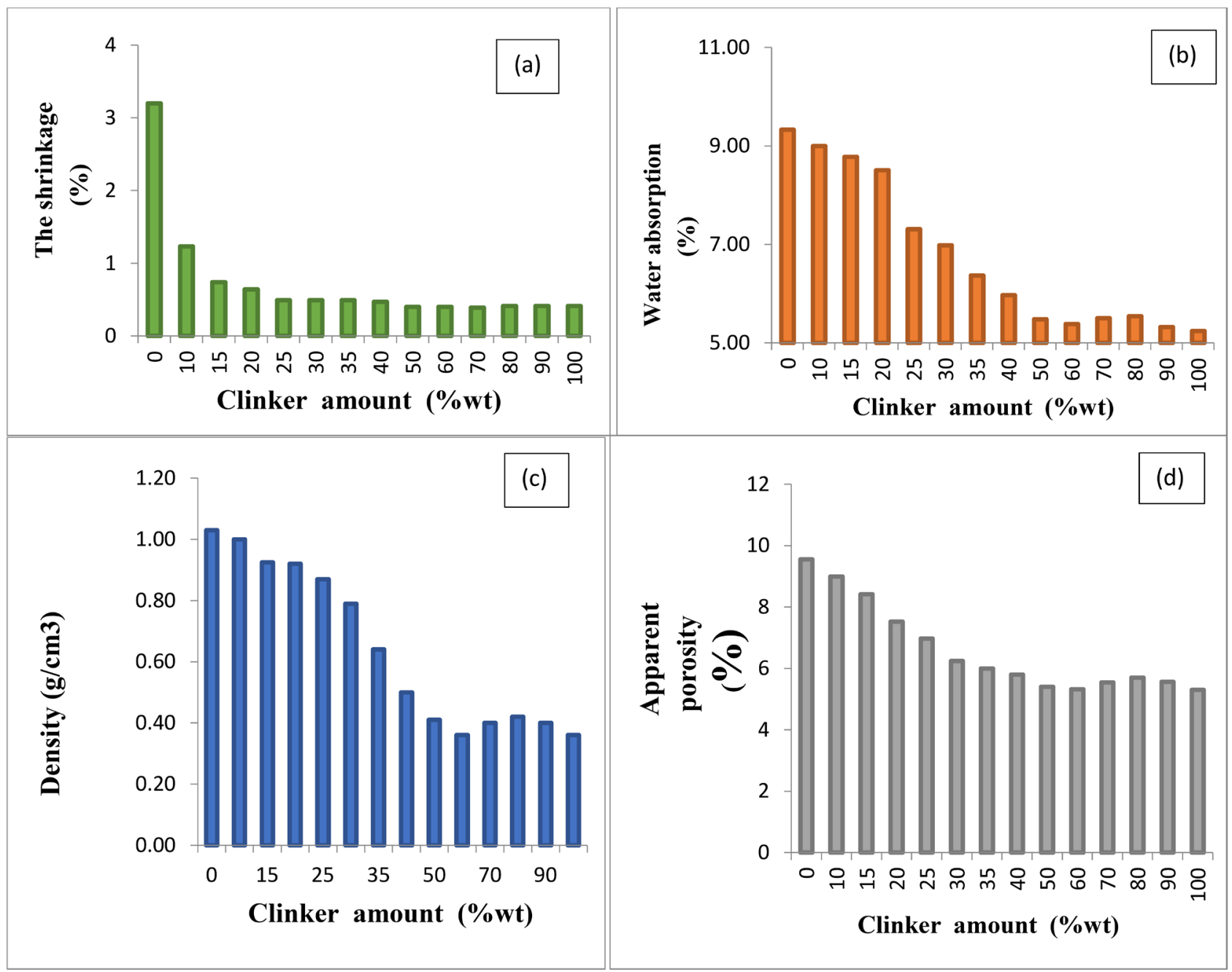

Figure 5. (a). The shrinkage of the ceramic material samples (b). Water adsorption in red clay ceramic materials (c). Evolution of ceramic materials density (d). Apparent porosity of the ceramic materials.

Adding amounts of the clinker decreases the porosity of the pellets (6\% for $35 \%$ of clinker) (Figure 5(d)). The result of our work is the best comparing marble bricks (30\%) [20] with fly ash bricks (27.69\%) [19].

5) Chemical resistance

Chemical attack using different liquids was performed on pellets, the samples were put at $25^{\circ} \mathrm{C}$ into a bath of hydrochloric acid $(\mathrm{pH}=1)$, sulfuric acid $(\mathrm{pH}=$ $1)$, nitric acid $(\mathrm{pH}=1)$ and sodium hydroxide $(\mathrm{pH}=13.5)$. The weight was checked regularly after every 24 hours for 2 weeks. The samples were then washed with distillated water and dried. The weight loss using attack by acid and basic solutions as a function of duration was collected (Figure 6(a)). The most corrosive solution for our composite materials was the sulfuric acid and the hydrochloric acid. Also chemical resistance decreases with the addition of clinker (Figure 6(b)).

6) The mechanical properties

The values of the mechanical properties for different amount of clinker (Table 4). 


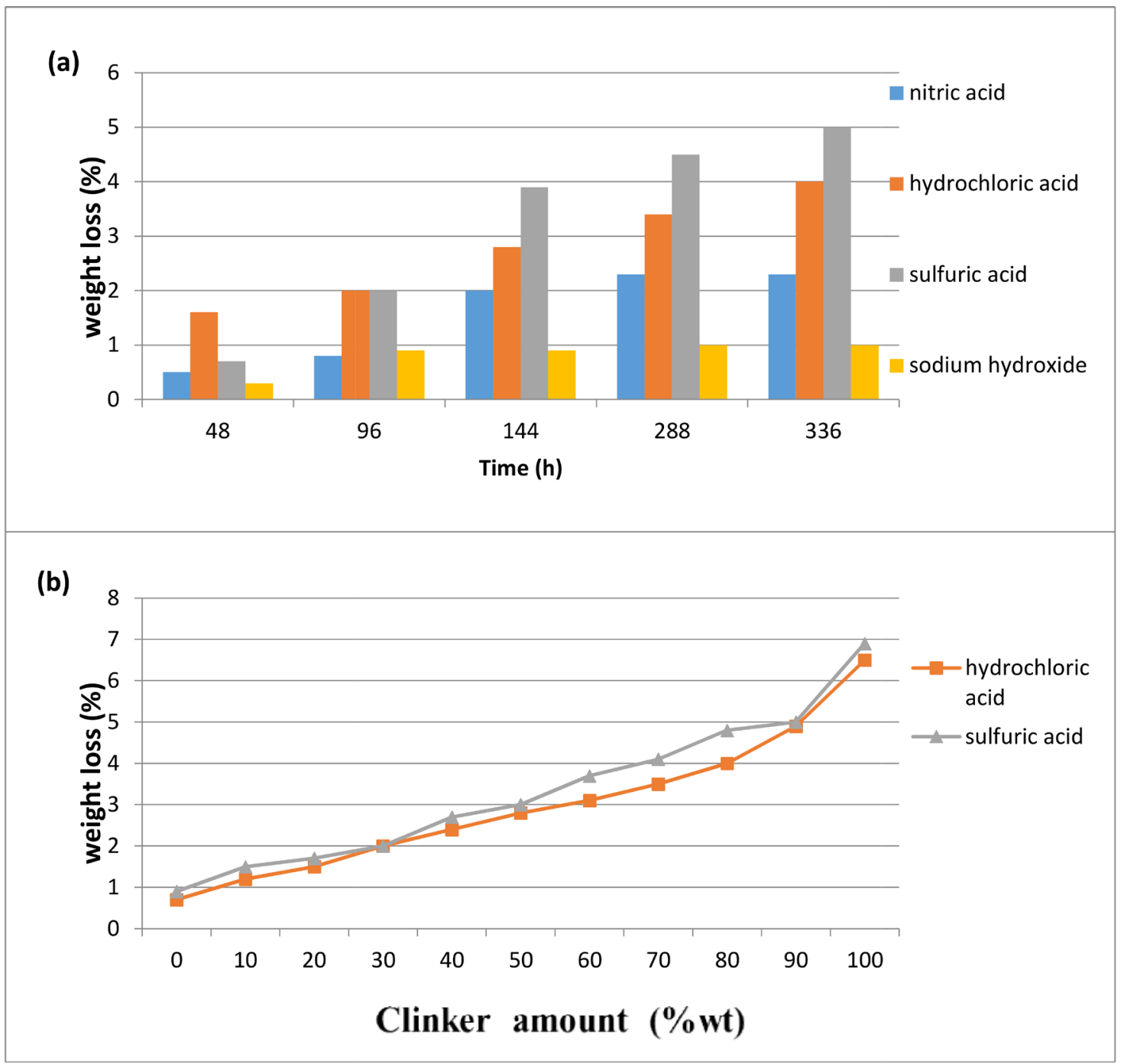

Figure 6. (a) Chemical resistance for $\mathrm{HNO}_{3}, \mathrm{HCl}, \mathrm{H}_{2} \mathrm{SO}_{4}$ and $\mathrm{NaOH}$ (b). Chemical resistance for $\mathrm{HCl}$ and $\mathrm{H}_{2} \mathrm{SO}_{4}$ as function of clinker amount.

It may be noted that those mechanical properties are influenced by the amount of clinker. Increasing the proportion of clinker gives an increase in mechanical strength. All other studies have found low mechanical strength and young's modulus compared to this study [13]-[18].

Results of the compressive and flexural strength for the produced ceramic materials as a function of clinker amount and firing at $1100^{\circ} \mathrm{C}$ are presented in Figure 7.

Clinker addition caused an increase in strength up to $50 \mathrm{wt} \%$, samples between 50 and $100 \mathrm{wt} \%$ clinker exhibited similar strength values. The higher strength value found for $60 \mathrm{wt} \%$ clinker, it is due to their ceramics and glass-ceramic composites [22] [23], the values of Young's modulus varied between 0.2 and 3.94 GPa, which are comparable to those of some siliceous ceramic materials quoted in the literature [23] [24] [25]. The ratio of Young's modulus to flexural strength was between 70 and 250 in agreement with the most ceramic materials [23]. 
Table 4. The mechanical properties of the composite ceramic material with different amounts of clinker.

\begin{tabular}{cccccc}
\hline $\begin{array}{c}\text { clay } \\
(\mathrm{wt} \%)\end{array}$ & $\begin{array}{c}\text { Clinker amount } \\
(\mathrm{wt} \%)\end{array}$ & $\begin{array}{c}\text { Compressive } \\
\text { Strength }(\mathrm{MPa})\end{array}$ & $\begin{array}{c}\text { Deplacement } \\
(\mathrm{mm})\end{array}$ & RMF(MPa) & $\begin{array}{c}\text { Young's Modulus } \\
(\mathrm{MPa})\end{array}$ \\
\hline 100 & 0 & 10.37 & 1.13 & 3.20457 & 207 \\
90 & 10 & 15.37 & 1.12025 & 8.2235 & 746.23 \\
85 & 15 & 24.18 & 0.80956 & 10.2435 & 1237 \\
80 & 20 & 30.28 & 0.62263 & 12.39684 & 1586 \\
75 & 25 & 38.45 & 0.52606 & 13.41083 & 3425 \\
70 & 30 & 39.18 & 0.52606 & 14.1423 & 3425 \\
65 & 35 & 40.85 & 0.52606 & 16.42003 & 3484 \\
60 & 40 & 42.87 & 0.52603 & 18.76814 & 3819 \\
50 & 50 & 44.91 & 0.52602 & 19.43189 & 3876 \\
40 & 60 & 45.91 & 0.52591 & 20.44 & 3971 \\
30 & 70 & 45.53 & 0.52601 & 21.4399 & 3960 \\
20 & 80 & 45.47 & 0.52606 & 21.43874 & 3954 \\
10 & 90 & 45.4 & 0.52611 & 21.87758 & 3948 \\
0 & 100 & 45.37 & 0.52616 & 21.74364 & 3935 \\
\hline
\end{tabular}

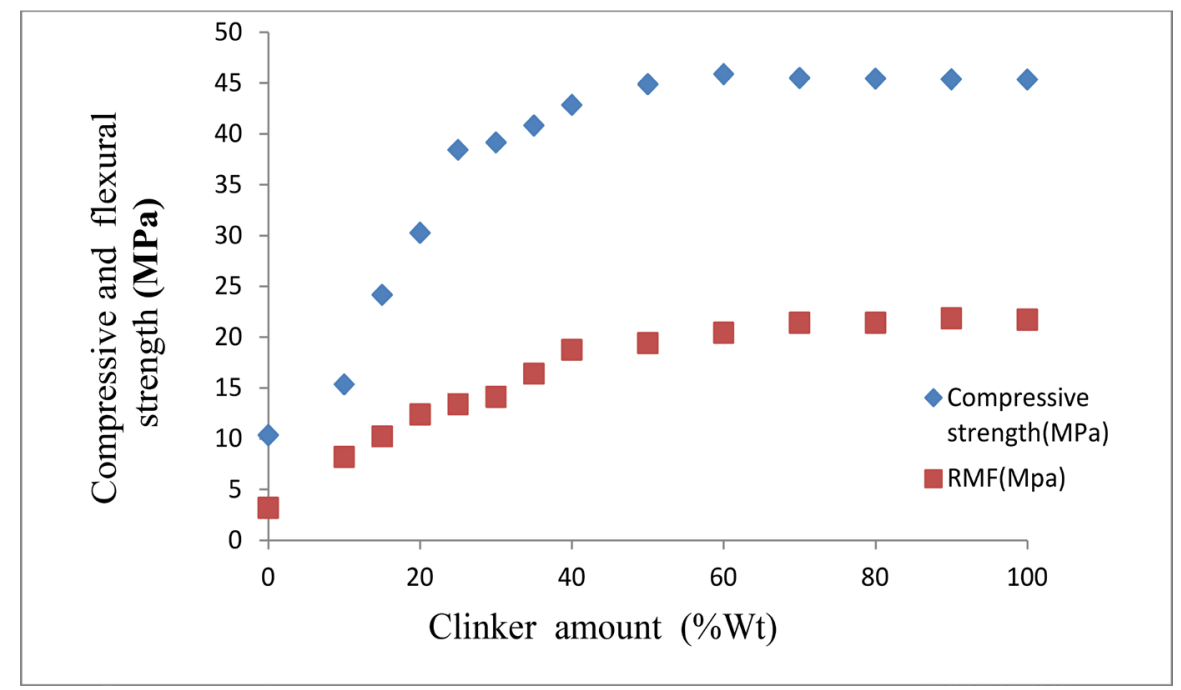

Figure 7. Compressive and flexural strength versus clinker content $t$ in clay based ceramics.

\section{7) Structure study}

The best mechanical properties were demonstrated by the ceramics start with compositions containing a $50 \mathrm{wt} \%$ clinker content. Therefore, samples were chosen for the study of physical processes involved in the physico-chemical interaction between the components of these mixtures during sintering and to study the structure of the obtained ceramic materials.

The morphology and distribution of the different phases and of porosity in sintered samples were analyzed by microstructural observation. SEM micrographs (Figure 8) for clay samples ((a) and (b)) and for clay with $50 \mathrm{wt} \%$ clinker 


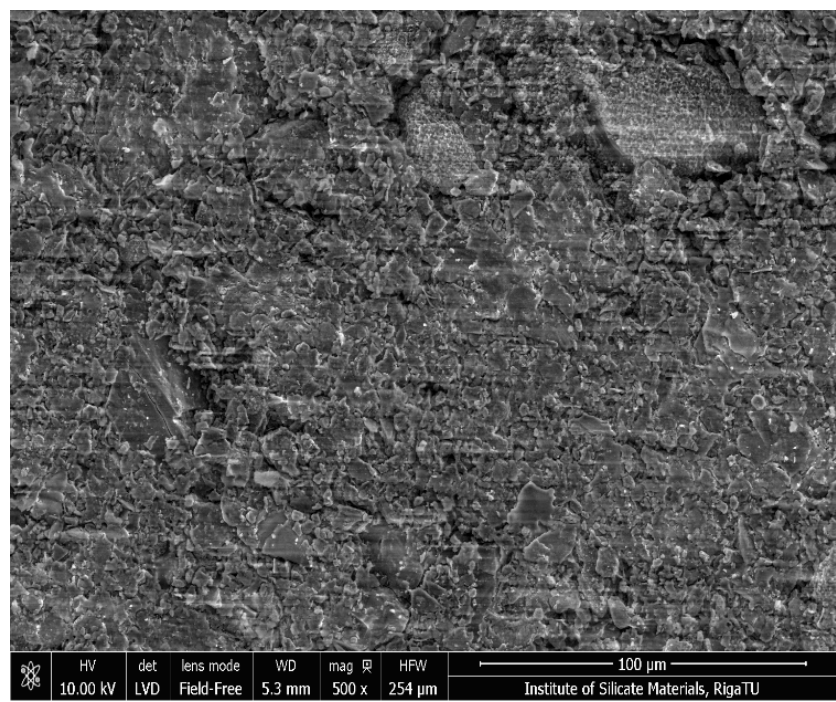

(a)

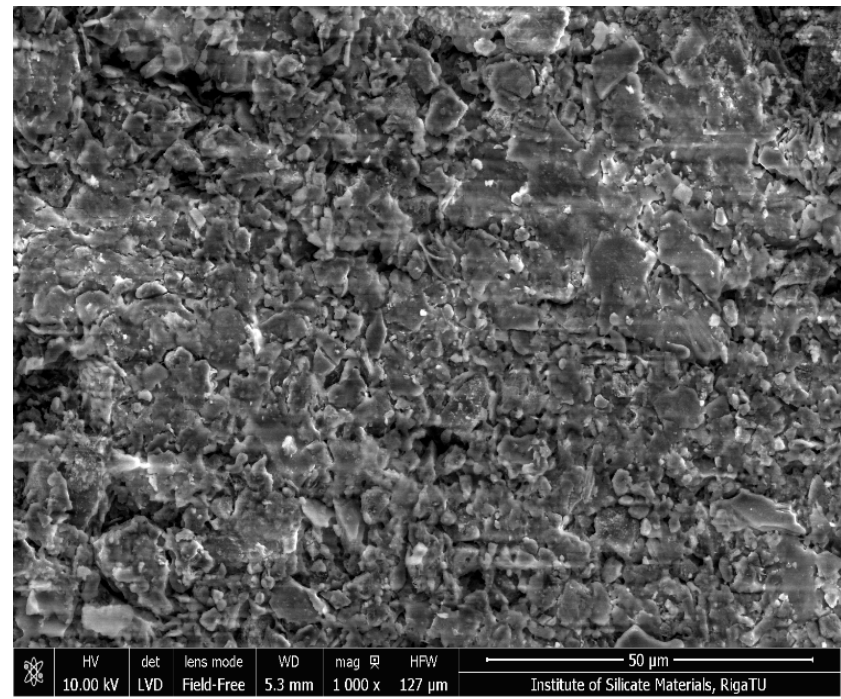

(b)

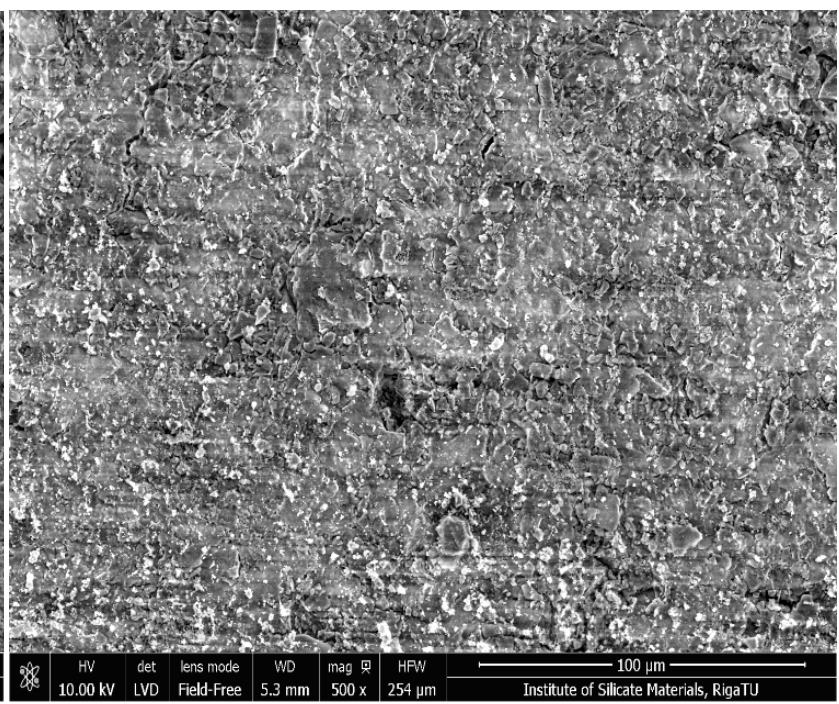

(c)

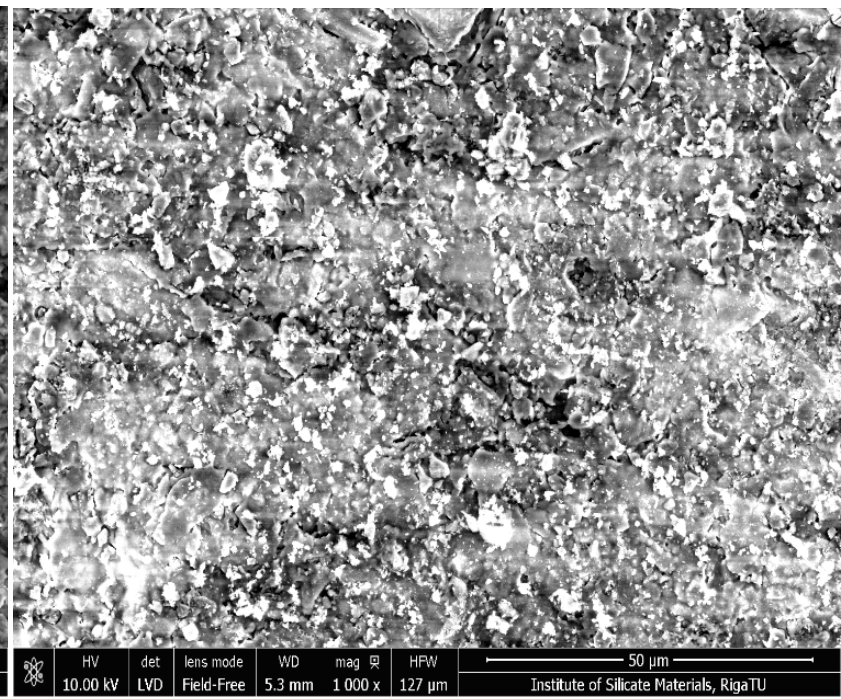

(d)

Figure 8. Scanning electron micrographs of fractured surfaces of clay ((a) and (b)) and of clay $+50 \mathrm{wt} \%$ clinker ((c) and (d)), sintered at $1100^{\circ} \mathrm{C}$.

((c) and $(\mathrm{d}))$, sintered for $8 \mathrm{~h}$ at $1100^{\circ} \mathrm{C}$, showed that microstructure $\mathrm{A}$ and $\mathrm{B}$ got a higher amount of interconnected pores than microstructure $\mathrm{C}$ and $\mathrm{D}$, where the pores appear to be more elongated. The ceramic material with $50 \mathrm{wt} \%$ of clinker is denser than the clay, which is in agreement with the density and water absorption behaviors shown by these samples.

The weaker densification observed in samples containing a less amount of clinker is due to a smaller content of oxides that would act as fluxing agents (e.g. $\mathrm{CaO}, \mathrm{Na}_{2} \mathrm{O}$ and $\mathrm{Ka}_{2} \mathrm{O}$ ) comparatively to clay (Table 2), and also to the presence of carbonate. This will react during the firing process contributing to increase the porosity of the final material. Achievement of high density is important because the mechanical properties of the obtained products will improve with the increase in the final density. 
The EDS analysis (Table 5) of the chemical composition of the raw materials was consistent with the XRF (Table 2) and XRD (Figure 4) analysis results. The main inorganic component of clinker is calcium in amorphous or partially crystalline form, as well as calcite.

Six test's spots are marked in each sample (Figure 9), and in the results of the elemental analyses presented (Table 5).

The ceramic material presented high silicon and magnesium content due to the presence of quartz and cristobalite and rather average amounts of sodium (Na) typical in most ceramics high $\mathrm{Si}$ and $\mathrm{Al}$ contents, which were in illite, as well as iron and minor amounts of other elements. Comparison of the results of chemical analysis of the composite materials by two methods XRF (Table 2) and EDS (Table 5) reveals their significant difference, especially in the number of $\mathrm{Si}$,

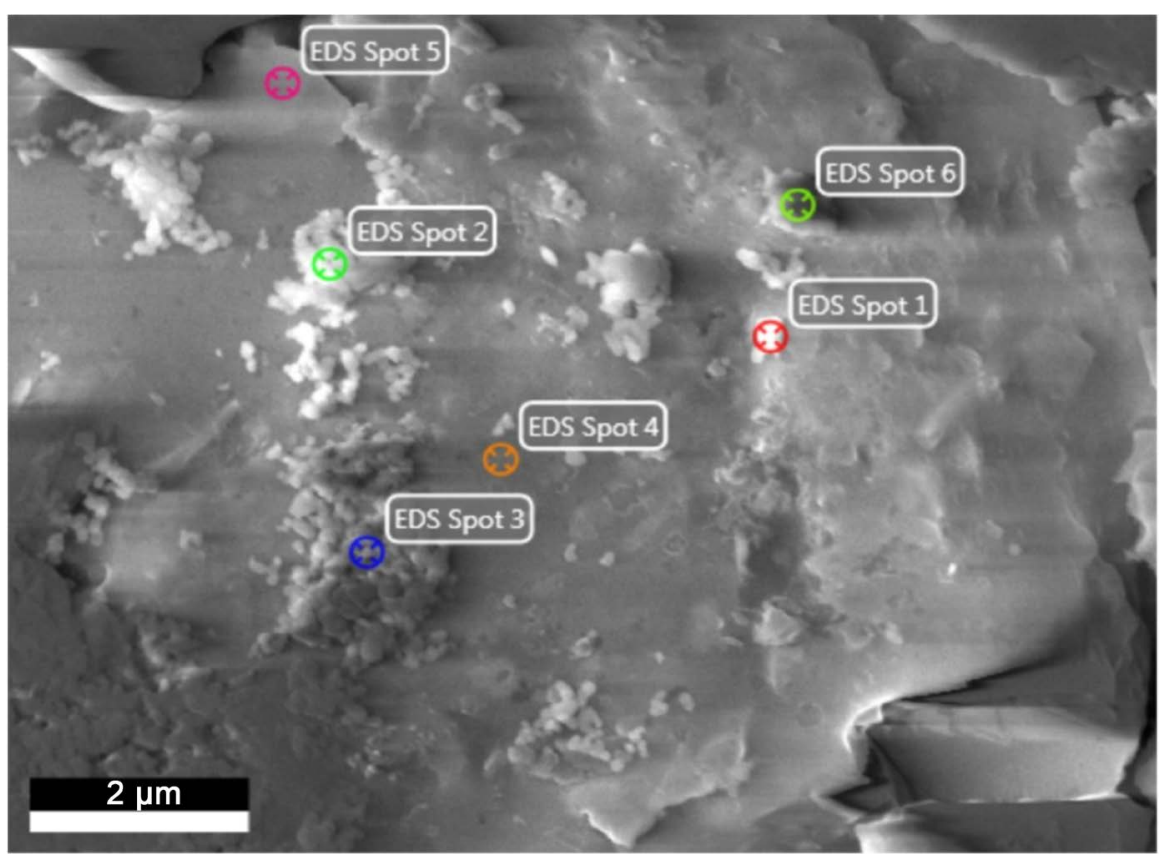

Figure 9. SEM micrographs for EDS analysis of sample (50 wt\% clinker) sintered at $1100^{\circ} \mathrm{C}$.

Table 5. Chemical compositions of the spots of the ceramic material $50 \mathrm{wt} \%$ clinker (by EDS method).

\begin{tabular}{|c|c|c|c|c|c|c|c|c|c|c|}
\hline & \multicolumn{10}{|c|}{ Elements wt $\%$} \\
\hline & $\mathrm{O}$ & $\mathrm{Na}$ & $\mathrm{Mg}$ & $\mathrm{Al}$ & $\mathrm{Si}$ & $\mathrm{P}$ & K & $\mathrm{Ca}$ & $\mathrm{Fe}$ & $\mathrm{C}$ \\
\hline Spot 1 & 48.02 & 1.03 & 4.81 & 4.27 & 36.97 & 0.5 & 1.44 & 0.89 & 2.08 & \\
\hline Spot 2 & 43.46 & 0.69 & 4.06 & 7.52 & 20.26 & 0.1 & 2.5 & 4.99 & 3.5 & 12.93 \\
\hline Spot 3 & 42.84 & 0.74 & 5.09 & 6.55 & 30.12 & 0.23 & 1.94 & 0.74 & 3.09 & 8.67 \\
\hline Spot 4 & 38.05 & 0.71 & 1.58 & 8.87 & 29.95 & 0.33 & 2.97 & 1.28 & 7.88 & 8.36 \\
\hline Spot 5 & 31.45 & 0.19 & 1.26 & 10.98 & 30.19 & 0.4 & 3.51 & 2.49 & 7.96 & 11.57 \\
\hline Spot 6 & 50.18 & 1.74 & 1.58 & 5.03 & 24.94 & 0.51 & 1.58 & 1.81 & 3.41 & 9.22 \\
\hline
\end{tabular}


$\mathrm{Al}$ and partly of $\mathrm{Ca}$. This difference is determined by the following reason: XRF provides information about the composition of the whole volume of the sample, and EDS only in its composition at three points; at the same time clinker is extremely difficult material for its characterization by EDS method because of its high content of well visible particles of various diameters and lengths. XRF provides results in the form of oxides, and EDS as only the chemical elements.

\section{Conclusions}

The results obtained in this work showed that the clinker from cement industry with content up to $50 \mathrm{wt} \%$, can be used in the production of ceramics using a red clay matrix.

Shrinkage values decreases as the amount of clinker increases, low shrinkage reduces the risk of defects such as warping and cracking.

Water absorption and porosity decreases as the amount of clinker increases witch lead to a better densification of the composite ceramic material, although the chemical attacks on the ceramic materials give more weight losses as the amount of clinker increases.

Mechanicals strengths of the samples are within the range of $20-45 \mathrm{MPa}$. Those new compositions of ceramic materials demonstrated better mechanical properties than conventional materials heated at $1100^{\circ} \mathrm{C}$.

Both physical and chemical analysis of these composite ceramic materials indicated that the sintering and melting caused the formations of vitreous and amorphous phases with inclusions of some crystalline phases such as muscovite dolomite and calcite.

\section{References}

[1] Bergaya, F. and Lagaly, G. (2006) General Introduction: Clays, Clay Minerals, and Clay Science. In: Bergaya, F., Theng, B.K.G. and Lagaly, G., Eds., Handbook of Clay Science, Vol. 1, Elsevier, New York, 1224.

[2] Guggenheim, S. and Martin, R.T. (1995) Definition of Clay and Clay Mineral: Joint Report of the AIPEA Nomenclature and CMS Nomenclature Committees. Clays and Clay Minerals, 43, 255-256; Clay Minerals, 30, 257-259.

[3] Occelli, M.L. and Robson, H.E. (1992) Expanded Clays and Other Microporous Solids. In: Occelli, M.L. and Robson, H.E., Eds., Synthesis of Microporous Materials, Vol. 2, Van Nostrand Reinhold, New York, 282-295.

[4] Kalkan, E. (2006) Utilization of Red Mud as a Stabilization Material for the Preparation of Clay Liners. Engineering Geology, 87, 220-229. https://doi.org/10.1016/j.enggeo.2006.07.002

[5] Greene, R.S.B., Eggleton, R.A. and Rengasamy, P. (2002) Relationships between Clay Mineralogy and the Hardsetting Properties of Soils in the Carnarvon Horticultural District of Western Australia. Applied Clay Science, 20, 211-223. https://doi.org/10.1016/S0169-1317(01)00073-4

[6] Felhi, M., Tlili, A., Gaied, M.E. and Montacer, M. (2008) Mineralogical Study of Kaolinitic Clays from Sidi El Bader in the Far North of Tunisia. Applied Clay Science, 39, 208-217. https://doi.org/10.1016/j.clay.2007.06.004 
[7] de Senna, J.A., Filho, C.R.S. and Angélica, R.S. (2008) Characterization of Clays Used in the Ceramic Manufacturing Industry by Reflectance Spectroscopy: An Experiment in the São Simão Ball-Clay Deposit, Brazil. Applied Clay Science, 41, 85-98. https://doi.org/10.1016/j.clay.2007.10.004

[8] Macfadyen, J.D. (2006) Cement and Cement Raw Materials. In: Kogel, J.E., Trivedi, N.C., Barker, J.M. and Krudowski, S.T., Eds., Industrial Minerals and Rocks, 7th Edition, SME, Littleton, Colorado, 1121-1136.

[9] Elaboration, J.R. (2005) Microstructure and Behavior of Polymer Matrix Composite Materials. Hermes, 376.

[10] Carvalho, L.H., Canedo, E.L., Farias Neto, S.R., Barbosa de Lima, A.G. and Silva, C.J. (2013) Moisture Transport Process in Vegetable Fiber Composites: Theory and Analysis for Technological Applications. In: Delgado, J.M.P.Q., Ed., Industrial and Technological Applications of Transport in Porous Media, Springer, Berlin, 37-62. https://doi.org/10.1007/978-3-642-37469-2_2

[11] Berthelot, J.-M. (2012) Composite Materials: Mechanical Behavior and Structural Analysis. 5th Edition, TEC \& DOC, Lavoisier.

[12] ASTM C20-00 (2015) Standard Test Methods for Apparent Porosity, Water Absorption, Apparent Specific Gravity, and Bulk Density of Burned Refractory Brick and Shapes by Boiling Water. ASTM International, West Conshohocken, PA.

[13] ASTM C356 (2010) Standard Test Method for Linear Shrinkage of Preformed High-Temperature Thermal Insulation Subjected to Soaking Heat. ASTM International, West Conshohocken, PA.

[14] ASTM C674-88 (1999) Standard Test Methods for Flexural Properties of Ceramic Whiteware Materials. ASTM International, West Conshohocken, PA.

[15] Levin, E.M., Robbins, C.R. and McMurdie, H.F. (1964) Phase Diagrams for Ceramists. Vol. 1, The American Ceramic Society, Inc., OH, USA, 219-241.

[16] Ajam, L., Ouezdou, M.B., Felfoul, H.S. and Mensi, R. (2009) Characterization of the Tunisian Phosphogypsum and Its Valorization in Clay Bricks. Construction and Building Materials, 23, 3240-3247. https://doi.org/10.1016/j.conbuildmat.2009.05.009

[17] Arib, A., Sarhiri, A. and Moussa, R. (2007) Influence of the Feldspar Composition on the Structural and Mechanical Characteristics of Clay-Based Ceramics. Comptes Rendus Chimie, 10, 502-510. https://doi.org/10.1016/j.crci.2006.01.005

[18] ASTM C373-88 (2006) Standard Test Method for Water Absorption, Bulk Density, Apparent Porosity, and Apparent Specific Gravity of Fired Whiteware Products. ASTM International, West Conshohocken, PA.

[19] Xu, L.L., Guo, W., Wang, T. and Yang, N. (2005) Study on Fired Bricks with Replacing Clay by Fly Ash in High Volume Ratio. Construction and Building Materials, 19, 243-247. https://doi.org/10.1016/j.conbuildmat.2004.05.017

[20] Sutcu, M. (2015) Characteristics of Fired Clay Bricks with Waste Marble Powder Addition as Building Materials. Construction and Building Materials, 82, 1-8. https://doi.org/10.1016/j.conbuildmat.2015.02.055

[21] Mekki, H. (2003) Recycling of Waste from the Crushing of Olives in Building Bricks. Annales de Chimie Science des Matériaux, 28, 109-127. https://doi.org/10.1016/S0151-9107(03)00010-2

[22] Ferraris, M., Salvo, M., Smeacetto, F., Augier, L., Barbieri, L., Corradi, A. and Lancellotti, I. (2001) Glass Matrix Composites from Solid Waste Materials. Journal of the European Ceramic Society, 21, 453-460. 
https://doi.org/10.1016/S0955-2219(00)00236-3

[23] Appendino, P., Ferraris, M., Matekovits, I. and Salvo, M. (2004) Production of Glass-Ceramic Bodies from the Bottom Ashes of Municipal Solid Waste Incinerators. Journal of the European Ceramic Society, 24, 803-810.

[24] Hauert, A., Rossoll, A. and Mortensen, A. (2009) Young's Modulus of Ceramic Particle Reinforced Aluminum: Measurement by the Impulse Excitation Technique and Confrontation with Analytical Models. Composites Part A: Applied Science and Manufacturing, 40, 524-529. https://doi.org/10.1016/j.compositesa.2009.02.001

[25] Węglewski, W., Bochenek, K., Basista, M., Schubert, T., Jehring, U., Litniewski, J. and Mackiewicz, S. (2013) Comparative Assessment of Young's Modulus Measurements of Metal Ceramic Composites Using Mechanical and Non-Destructive Tests and Micro-CT Based Computational Modeling. Computational Materials Science, 77, 19-30. https://doi.org/10.1016/j.commatsci.2013.04.007 